WP 17-20

Eleftherios Goulas

Bedfordshire University, UK

Athina Zervoyianni

University of Patras, Greece

The Rimini Centre for Economic Analysis

\title{
ACTIVE LABOUR-MARKET POLICIES AND OUTPUT GROWTH \\ - IS THERE A CAUSAL RELATIONSHIP?
}

Copyright belongs to the author. Short sections of the text, not exceeding three paragraphs, can be used provided proper acknowledgement is given.

The Rimini Centre for Economic Analysis (RCEA) was established in March 2007. RCEA is a private, nonprofit organization dedicated to independent research in Applied and Theoretical Economics and related fields. RCEA organizes seminars and workshops, sponsors a general interest journal The Review of Economic Analysis, and organizes a biennial conference: The Rimini Conference in Economics and Finance (RCEF). Scientific work contributed by the RCEA Scholars is published in the RCEA Working Papers and Professional Report series.

The views expressed in this paper are those of the authors. No responsibility for them should be attributed to The Rimini Centre for Economic Analysis. 


\title{
ACTIVE LABOUR-MARKET POLICIES AND OUTPUT GROWTH - IS THERE A CAUSAL RELATIONSHIP?
}

\author{
Goulas Eleftherios* and Zervoyianni Athina ${ }^{* *}$
}

July 2017

\begin{abstract}
While the labour-market impact of ALMP interventions has been extensively studied, an issue that has not been widely addressed in the literature is to what extent active labour-market policies have beneficial effects for the whole economy at the macroeconomic level. This paper addresses this issue by examining how additional resources allocated to active labour-market policies relate to output-growth rates. It also examines the sensitivity of the growthALMP relationship to the economy's business-cycle position and the state of market expectations. Using data from OECD countries during 1991-2011, we find evidence of a positive output-growth differential due to implementing active labour-market policies in normal times of between 0.004 and 0.005 percentage point. This differential becomes larger during economic upturns and when market expectations are optimistic. These results are obtained after controlling for other standard, direct and indirect, influences on output-growth rates and after addressing the issue of potential endogeneities.
\end{abstract}

Key words: output growth; labour-market policy; cyclical influences

JEL Classification: E60, E23, J08, E30

*Department of Law \& Finance, Bedfordshire University, UK, Email: Eleftherios.Goulas@beds.ac.uk

*** (corresponding author) Department of Economics, University of Patras, Patras, Greece, Email: athina@ upatras.gr 


\section{Introduction}

Active labour-market policies (ALMPs) are implemented in many countries, either as a primary instrument for increasing labour-market flexibility or as part of an overall strategy for enhancing social cohesion (Casey, 2004; European Commission, 2006; Bonoli, 2010; Duell \&Vogler-Ludwig, 2012). ALMPs typically include job-search assistance services, training programs, subsidized employment aiming to raise labour demand, and measures targeting groups with special labour-market difficulties (e.g. youth, disabled individuals, low-skill employed workers at risk). Between 2000 and 2015, and excluding the crisis period 2008-2010, the amount of public funds allocated to such policies in OECD countries has grown at an average annual rate of $6 \%$, while today ALMP-spending in the OECD area accounts for almost $40 \%$ of the overall labour-market-policy budget. Interest in active labour-market policies has also been growing rapidly in developing countries in recent years, as governments in these economies increasingly see ALMPs as a tool capable of both improving labour-market efficiency and reducing poverty (Betcherman et al., 2004; Auer et al., 2008; Kuddo, 2009).

An extensive empirical literature currently exists that evaluates ALMPs from a microeconomic perspective, estimating, based on individual-level administrative data, how particular programs affect the unemployment-exit and employment-entry probabilities of participants. While the estimated program-outcomes vary between the different studies, there is growing evidence indicating that ALMPs have significant positive effects at the individual level (OECD, 2005, 2015). On the other hand, at the aggregate level, the effects of active labour-market policies remain controversial. Single-country studies using administrative data at national or regional level to take into account indirect consequences of programs for non-participants often find small overall program-impacts, while the findings of the macroeconomic literature, which uses cross-country data to estimate effects of ALMP-spending on aggregate employment or unemployment, are quite mixed (Baker et. al., 2005; Bassanini \& Duval, 2006; Martin, 2015). At the same time, cross-country analyses of overall ALMP-effects at the macroeconomic level, including general-equilibrium consequences of active labour-market policies such as effects on growth, are lacking. The objective of this paper is to provide broad cross-country evidence on whether or not active labour-market policies have beneficial macro-level effects for the whole economy by examining how additional resources allocated to ALMPs relate to output-growth rates.

Is there an output-growth gain from allocating additional resources to active labour-market policies? To what extent does the impact of ALMPs on growth depend on the state of the economy? Do active labour-market policies have the same growth consequences in 'good' and 'bad' times? So far these questions have not been explicitly addressed in the literature, despite the fact that the issue of whether or not ALMPs matter for growth has recently become particularly relevant due to the poor growth performance of many economies and the constrained fiscal budgets worldwide which have increased the opportunity cost of financing ALMPs. This paper seeks to add to the current literature by testing for a causal relationship between public spending on active labour-market policies and output growth and examining its sensitivity to cyclical influences and to changing market expectations. We use data from 
OECD countries ${ }^{1}$ during 1991-2011, while we control for other standard, direct and indirect, determinants of outputgrowth rates and for potential endogeneities. A simple model is initially identified to help clarifying the possible links between ALMP-spending and output-growth.

The empirical results indicate that active labour-market policies have a net growth-enhancing effect during normal times. The growth differential due to implementing ALMPs in normal times is found to be between 0.004 and 0.005 percentage point. This differential becomes larger during economic upturns and when market sentiment is optimistic.

Our findings have important policy implications in suggesting that implementing active labour-market policies is on average worthwhile from the perspective of the whole economy, even when the corresponding programs do not contribute much to raising the total number of jobs in the short run. At the same time, our results have implications with respect to the optimal timing of expanding ALMPs. From a microeconomic perspective, increasing the scale of ALMP-operations in the economy appears rational during downturns when unemployment is rising. But more ALMP-spending during periods of unfavourable economic conditions and deteriorating market sentiment may not lead to the maximum return from active labour-market policies in terms of per-capita output growth. Indeed, while it may seem appealing for governments to expand ALMPs in 'bad' times, our results suggest that the output-growth gain from more ALMP-spending is larger in 'good' times. There appears therefore to be an issue as to when additional active labour-market policies should be implemented. If policymakers' ultimate objective is higher per-capita outputgrowth, our results suggest that active labour-market policies might need to be overall more expansive when economic conditions are improving.

The rest of the paper is organized as follows. Section 2 briefly discusses the existing empirical literature, focusing on macro-level effects of ALMPs. Section 2 uses a simple analytical model to examine some key links between active labour-market policies and output growth. Section 4 presents the empirical specification and reports the estimation results. Section 5 contains concluding comments.

\section{Active labour-market policies}

Over the last decade a great deal of research effort has been devoted to providing estimates of the effects of ALMPinterventions on labour-market outcomes. A large part of this literature uses country-based micro-level data and focuses on how the employment situation of individual workers is affected by their participation in programs. While the estimated program-outcomes vary, depending on the country considered, type of program and length of observation period, most papers report evidence indicating that, at the individual level, active labour-market policies yield significant benefits. This is confirmed by several evaluation surveys and meta-analyses of the findings of conventional

\footnotetext{
${ }^{1}$ Australia, Austria, Belgium, Canada, Czech Republic, Denmark, Finland, France, Germany, Greece, Hungary, Ireland, Israel, Italy, Japan, Korea, Mexico, Netherlands, New Zealand, Norway, Poland, Portugal, Spain, Sweden, Switzerland, United Kingdom, United States. The country sample follows from data availability for all the variables.
} 
microeconomic approaches, which suggest that programs providing job-search assistance, training and private-sector employment-incentives pay off at the individual level, as workers who have participated in such programs are more likely to find or maintain a job over the medium or long term than workers who have never participated (Card et.al., 2010, 2015; Kluve, 2010; OECD, 2015). But while the standard microeconomic approach to evaluating ALMPs is of great importance in establishing whether or not the existing programs have achieved their intended effect at the individual level, it cannot determine the overall outcome in the labour market as potential indirect consequences of programs for non-participants are not taken into account. Accounting for such consequences, a number of recent micro-based studies find evidence of a smaller average impact of programs compared to what standard microeconometric analyses would suggest (Lise et. al., 2004; Ferraci et.al., 2008; Crepón et.al., 2013; Gautier et.al., 2015). ${ }^{2}$ Other single-country studies use administrative panel data on transition rates from unemployment into employment at the regional level to examine the overall labour-market outcome of particular programs. The findings of this literature are mixed, with some studies suggesting a sizable positive effect of the programs considered on the total number of jobs, while other papers report results indicating a small or statistically insignificant overall program-impact (Hujer \& Zeiss 2006; Fertig et. al.2006; Hujer et.al. 2009; Dauth et. al. 2010; Arranz et. al. 2013). ${ }^{3}$

The evidence from the macroeconomic literature, which tests for an effect of implementing active labour-market policies on aggregate unemployment or employment using cross-country panel data, is also quite mixed. In particular, while most authors conclude that program-spending matters for labour-market performance, there is no general consensus on the magnitude of the effect as the existing studies often differ in the way they model ALMP impacts, or in the way they measure the ALMP variable, with some papers using synthetic indicators of program-spending that are not invariant to labour-market conditions. For example, using a synthetic measure of ALMP-expenditures and estimating a reduced-form model of institutional determinants of unemployment in OECD countries, Nickell (1977) found a large unemployment-reducing effect from implementing active labour-market during the 1980s. Scarpetta (1996) and

\footnotetext{
${ }^{2}$ Crépon et.al. (2013), based on a clustered randomized experiment of a job-placement-assistance program in France, find evidence indicating that the aggregate benefits from ALMP-programs can be much smaller than the individual benefits due to negative spillovers on non-participants. Ferracci et.al. (2008) also detect signs of negative spillovers on non-participants examining a training program in France. Gautier et. al. (2015) report similar results, showing smaller overall benefits compared to what a standard microeconometric analysis would suggest, based on a randomized experiment of a Danish job-search-assistance program. Lise et. al. (2004) reach the same conclusion by calibrating an equilibrium labour-market model to match, as a partial-equilibrium solution, the standard individual-level outcome of an incentive program in Canada. Albrecht et.al. (2009), on the other hand, using a calibrated equilibrium labour-market model with heterogeneous skills to examine the effectiveness of a training-program in Sweden, find more positive overall program-impacts when spillovers between treated and non-treated individuals are taken into account. Other micro-based studies indicating that the impact of programs can be very different when equilibrium effects are explicitly taken into account include Blundell et.al. (2004), Filges \& Larsen (2005) and Cahuc \& Le Barbanchon (2010).

${ }^{3}$ Hujer \& Zeiss (2006) have found positive aggregate effects only from programs of short duration in Germany during 2002-2004, while Fertig et. al. (2006) and Hujer et.al. (2009) find mostly non-significant effects from the programs they consider after controlling for regional characteristics and interdependencies. In a similar context, examining regional data on job-seeker rates in Austria during 2001-2007, Dauth et. al. (2010) find that only few programs, such as those involving wage subsidies, have resulted in favourable aggregate effects. Dahlberg \& Forslund (2005), using a large set of Swedish municipality data over the period 1987-1996, also find small overall positive effects from programs providing job-creation incentives, but their results indicate large positive aggregate effects from training. Arranz et. al. (2013), based on regional administrative data for a variety of programs in Spain during 1987-2010, including subsidized employment, job creation and vocational-training schemes, report results indicating small aggregate effects. On the other hand, based on Italian regional data during 1996-2002 and a panel-VAR model, Altavilla \& Caroleo (2006) find notably favourable aggregate effects from a variety of ALMPs.
} 
Elmeskov et.al. (1998), based on data over the same period, found no conclusive evidence, with their estimates suggesting a small, and in some cases non-significant, effect of higher ALMP-spending on unemployment. Baker et al. (2005), estimating an equation similar to Nickell (1977) with OECD data for 1985-1999, also found no statistically significant unemployment-reducing effect of ALMPs, while Boone \& Van Ours (2009) present results indicating that training significantly reduces unemployment but other categories of active labour-market policies have weak effects. On the other hand, focusing on the role of interactions between macroeconomic shocks and labour-market characteristics, Blanchard \& Wolfers (2000) and Bertola et.al (2001) found that a large part of the cross-country variation in OECDunemployment rates during the 1980s and 1990s could be explained by a combination of common shocks and different labour-market policies, including ALMPs. But while in Blanchard \& Wolfers (2000) the coefficients of the interacted terms of shocks and ALMP-expenditures were found clearly negative, suggesting reduced responsiveness of unemployment to shocks in countries that spend more on active labour-market policies, in Bertola et.al (2001) these terms were mostly non-significant. Bassani \& Duval (2006) report evidence similar to Blanchard \& Wolfers (2000), indicating an indirect unemployment-reducing effect of ALMPs through interactions with shocks, although, estimating with OECD data for 1985-2005 a standard reduced-form model of institutional determinants of unemployment, they find that the direct unemployment effect of active labour-market policies is non-robust to different proxies of ALMP intensity or estimation methods. De Serres \& Murtin (2013) find that while program-spending has a decreasing effect on unemployment during normal times, it can raise the sensitivity of unemployment to short-term economic fluctuations and this may on balance lead to higher total volatility of unemployment. Indeed, based on data from OECD countries during 1985-2010, De Serres \& Murtin (2014) present simulation results indicating that ALMPs in general fail, following an adverse shock, to reduce overall labour-market exposure, as measured by the cumulated amount of unemployment in excess of its long-term level.

On the other hand, Estevảo (2007), focusing on employment, and controlling for demand influences, openness, central-bank independence and other labour-market characteristics, finds that active labour-market policies have led to higher business-sector employment-rates in OECD countries during the 1990s but not during the 1980s. In a similar context, Zervoyianni et. al.(2014), controlling for GDP growth, globalization, central-bank independence and productivity developments, report results indicating that ALMPs contribute to raising employment growth, although the magnitude of the estimated effect appears to vary somewhat across different specifications. Escudero (2015), based on OECD employment data for 1985-2010 and taking into account ALMP-implementation characteristics, also finds that active labour-market policies have significant employment-increasing effects, although their estimates indicate that programspending is more effective in improving labour-market outcomes for low-skill workers than for the overall population.

Evidence on the relationship between active labour-market policies and GDP developments is very limited. Only few studies exist that use autoregressive estimation techniques to investigate how the short-run dynamics of output are affected by reform shocks, including greater use of ALMPs. Bouis et. al. (2012), for example, based on a panel autoregressive model estimated with data from OECD countries during 1985-2007, examine impulse responses of 
output to more expansive active labour-market policies, with their results showing that the short- and medium-term output impact of higher overall ALMP-spending is negative or insignificantly positive. Systematic cross-country empirical analyses of whether or not active labour-market policies matter for output growth, based on a structural model that explicitly takes into account other, direct and indirect, determinants of growth rates, are lacking.

At the same time, despite much discussion on whether or not active labour-market policies have different effects over the cycle, only a small number of papers have explicitly investigated this issue. Much of this literature focuses on the micro-level outcomes of particular programs, examining how cyclical fluctuations in aggregate unemployment or other relevant indicators affect the job-entry probabilities of program participants. The evidence reported is mixed (Røed \& Raaum, 2006; Staghøj et al.,2007; Lechner \& Wunsch, 2009; Forslund et al., 2011; McVicar \& Podivinsky (2010); Crepón et.al., 2013; Card et.al., 2015). For example, while the results in Røed \& Raaum (2006), McVicar \& Podivinsky (2010) and Crepón et.al. (2013) indicate that program impacts are less positive when aggregate unemployment is higher or business-cycle conditions are unfavourable, the evidence reported in Lechner \& Wunsch (2009), Forslund et al. (2011) and Card et.al. (2015) suggests that program-outcomes are more positive when unemployment is higher. ${ }^{4}$

Evidence from macroeconomic studies on the role of the business cycle in ALMP-impacts is even scarcer and conclusions regarding the direction of the effect are not clear-cut. For example, Altavilla \& Caroleo (2013), using a panel-VAR model and regional data for Italy, find that the short-run employment gains from higher ALMP-spending are larger in relatively rich regions than in more depressed regions. Escudero (2015), based on a structural model estimated with OECD data for 1985-2010, finds that the employment-enhancing effects of active labour-market policies are weaker when ALMPs are implemented in a counter-cyclical manner. On the other hand, Bouis et. al. (2012), based on a panel autoregressive model estimated with OECD data for 1985-2007, report results suggesting no significant short- or medium-term impact of cyclical conditions on the response of output to greater use of ALMP-training or private-sector incentives, although their results indicate that other labour-market reforms generate more positive shortrun output-responses in good times than in bad times.

This paper seeks to add to the current literature in two ways. First, it examines whether or not implementing active labour-market policies generates on average a net gain for the whole economy at the macroeconomic level, by testing for an effect of additional ALMP-spending on per-capita output growth after controlling for other standard, direct and

\footnotetext{
${ }^{4}$ Lechner \& Wunsch (2009), examining classroom training in Germany over the period 1984-2003, find more positive outcomes at the individual level when unemployment is higher, and this is attributed to reduced lock-in costs at the individual level (associated with the drop of participants' job-search intensity). Forslund et al. (2011) report similar evidence, related to decreasing costs of lock-in effects at the individual level when overall labour-market conditions are unfavourable, using data on two different training programs in Sweden during 1999-2005. On the other hand, Røed \& Raaum (2006), based on a large set of Norwegian administrative data over a 14-year period, find that ALMP-impacts are less positive when business-cycle conditions are unfavourable. McVicar \& Podivinsky (2010), based on a set of administrative data over a 9-year period for a program for young individuals in the UK, report results in the same direction, with their estimates indicating that the overall effectiveness of the program is inversely related to local unemployment. Crepón et.al. (2013) reach a similar conclusion based on a clustered randomized experiment of a job-placement-assistance program in France, as their results show that the likelihood of large negative externalities from the program is greater in depressed areas with high unemployment than in other areas. By contrast, Card et.al. (2015), in a recent meta-analysis of the findings of conventional microeconometric-evaluation studies, conclude that programs are more likely to have large positive effects at the individual level during recessions than during booms. However, it is pointed out that this could be due to the different characteristics of program-participants during such times rather than the different effectiveness of the programs themselves.
} 
indirect, influences on growth rates. Second, it investigates the sensitivity of the growth-ALMP relationship to changing economic conditions, by allowing for an effect on the growth-ALMP elasticity of the economy's business-cycle position and state of market expectations. Indeed, while the literature lacks detailed theories of how active labourmarket policies relate to output-growth rates, there are several channels through which ALMPs can generate growth effects. Active labour-market policies can be growth-increasing through higher average productivity in the economy, by directing workers to jobs that are better suited to their qualifications or experience and by encouraging skill acquisition and human-capital development. Growth-increasing effects may also result from greater labour supply, as ALMPs, by improving participants' employability, provide incentives to the population for labour-force entry. Positive effects on growth may further result from lower equilibrium unemployment, to the extent that active labour-market policies, by reducing information asymmetries in the job-search process, can contribute to raising the average job-matching rate. Additional growth-enhancing effects may come from increased overall efficiency in the economy, as the better-quality job-matches and the improvement in the average competencies of the workforce can help speed up the pace of technical change. On the other hand, active labour-market policies require funding, and increasing the scale of ALMP operations in the economy can have adverse repercussions on growth by limiting the resources available for other, potentially more productive, public-sector uses or leading to extra taxes. By making unemployment less frightening, ALMPs can further lower growth through higher reservation wages or reduced average job-search effort in the economy (Van Ours, 2004; Røed \& Raaum, 2006; Rosholm \& Skipper, 2009). At the same time, the growth effect of active labour-market policies may not be independent of the economy's business-cycle position. For example, the opportunity cost of financing additional programs is likely to be higher during economic downturns, when the strain on public-sector resources is already sizable. The population's incentive to join the labour force and improve employability by participating in programs may also be weaker the more pessimistic are expectations regarding future earnings and thus the less satisfactory is the current state of the economy. In addition, any net negative effect of ALMPs on average jobsearch effort in the economy may well be more pronounced at times of unfavourable market expectations, when jobfinding rates are low anyway and the retum to search is small, something consistent with the findings of e.g. Bloemen (2005), Krueger \& Mueler (2011) and DeLoach \& Kurt (2013) which suggest that search effort is in general procyclical. And whether or not the positive consequences of ALMPs for output-growth can offset any negative sideeffects is a priori unclear.

\section{Output growth and active labour-market policies: theoretical underpinnings}

To help clarify some key links between active labour-market policies and per-capita output growth, in this section we examine a simple model with capital accumulation and ALMP-spending, assuming, in line with much of the ALMP literature (see e.g. Calmfors et.al, 2002; Brown \& Koettl, 2015; Crepón et.al., 2016), mismatch-frictions in the labour 
market and non-competitive wages. Thus, with ALMP-interventions in the economy, and with two inputs, labour units, $N$, and physical capital, $K$, and a Cobb-Douglas production technology, aggregate output, $Y$, can be described as

$$
\begin{gathered}
\left.Y=A K^{a}\left(E_{N} N\right)\right]^{(1-a)} \\
E_{N}=E_{N}(q), A=A_{o} E_{A}(q) \\
E_{N q}, E_{A q} \geq 0, A_{o}>0
\end{gathered}
$$

and per-capita output $y$ can be described as:

$$
\begin{gathered}
y=A_{o} E(q) k^{a}[\ell(1-u)]^{(1-a)} \\
E(q)=E_{A}(q)\left[E_{N}(q)\right]^{(1-a)}, E_{q} \geq 0
\end{gathered}
$$

$k$ is the per-capita capital stock, $\ell$ measures labour-force participation and $u$ is the unemployment rate. $E_{N}$ is a labourproductivity-augmenting factor, which, among other elements, may depend on the scale of ALMP-operations in the economy $q$, to the extent that active labour-market policies direct workers to jobs that are better-suited to their skills or experiences and also contribute to enhancing the average competencies of the workforce. $E_{A}$ is an efficiency-augmenting factor, which may also depend positively on the economy's ALMP intensity through externalities at the macroeconomic level, as the increase in the average skill-level and market experience of the workforce and the better-quality job-matches can facilitate innovation and can contribute to speeding up the pace of technological change.

At the same time, with ALMP-interventions in the economy, and given that some programs target new labourforce entrants (Calmfors \& Lang, 1995; Calliendo et. al. 2016), the decision of an individual whether or not to enter the labour force is likely to be influenced not only by labour-market conditions (Fallick \& Fleischman, 2004; Aaronson $e t$ al., 2006; Van Zandweghe, 2013; Erceg \& Levin, 2014), but also by the probability of participation in programs, itself depending, among other factors, on the economy's ALMP-intensity, to the extent that programs, by helping participants acquire the additional information, skill-level or market experience needed to find a regular job, provide increased employment prospects. Thus, at the aggregate level, in addition to improved conditions in the labour market, greater labour-force participation may also result from an increase in the scale of ALMP-operations in the economy (Johansson, 2001; Estevặo, 2007; Escudero, 2015), leading to (2):

$$
\begin{gathered}
\ell=\ell_{o}[1+\phi(\theta) f(q)] \\
\phi_{\theta}>0, f_{q} \geq 0
\end{gathered}
$$

$\theta$ is a measure of labour-market tightness ( $\phi_{\theta}>0$ ), while $f_{q}>0$ reflects, for a given $\theta$, the possibility of a positive effect on the labour-force-participation-decision of the population's perceived probability of program-participation, itself depending, among other factors, on the economy's ALMP-intensity. $\ell_{o}$ represents other (given) influences on the labour-force-participation decision.

On the other hand, with matching frictions in the labour market, the likelihood for a laid-off worker to find a job will, other things equal, depend on the economy-wide job-matching-rate $m_{r}$. Assuming a standard constant-returns-to-

\footnotetext{
${ }^{5}$ e. g. youth measures and other schemes targeting disadvantaged workers.
} 
scale matching function of the form $M=\mu V^{\gamma} U^{1-\gamma}$ (Petrongolo \& Pissarides, 2001) were $V$ and $U$ are, respectively, the stock of vacancies and the level of unemployment and $\mu$ is a shift parameter measuring matching efficiency, $m_{r}$ follows as $m_{r}=\mu(V / U)^{\gamma}, 0<\gamma<1$. Although, given the inverse relationship between $V$ and $U, m_{r}$ will vary over the cycle, causing the average job-finding probability to fluctuate independently of ALMPs, active labour-market policies could raise matching efficiency by reducing information asymmetries in the job-search process and contributing to a quicker adaptation of job-seekers' skills to the requirements of vacant jobs. Improved matching efficiency due to more ALMPs will then cause vacancies to be filled more quickly, increasing $m_{r}$ for a given $V$ and $U$ by raising $\mu$.Accordingly, defining $(V / U)$ as labour-market tightness $\theta$ (e.g. Pissarides, 2000), $m_{r}$ can be described by (3)

$$
m_{r}=\mu(q) \theta^{\gamma}, \mu_{q} \geq 0,
$$

where $\mu_{q}$ measures the matching-efficiency sensitivity to changes in the economy's ALMP intensity. With $m_{r}$ being determined by (3), and letting $s$ be average search effort in the economy and $\xi$ a given job-destruction rate, the behaviour over time of unemployment follows as

$$
\begin{aligned}
\dot{u} & =-s m_{r} u+\xi(1-u) \\
& =-s \mu(q) \theta^{\gamma} u+\xi(1-u),
\end{aligned}
$$

and the rate of change of unemployment, $\gamma_{u}=\dot{u} / u$, is given as:

$$
\gamma_{u}=-s \mu(q) \theta^{\gamma}+\xi\left(\frac{1}{u}-1\right), \mu_{q} \geq 0
$$

But while active labour-market policies will tend to decrease $\gamma_{u}$ through $\mu$, a counteracting, unemploymentincreasing, effect is possible to arise from the impact of ALMPs on $s$. Average job-search effort in the economy may well fall as a result of implementing active labour-market policies, not only because workers currently participating in programs will have reduced incentives or less time available for job search, but also because, by making unemployment less frightening, the prospect of potential program-participation, which increases with the scale of ALMP-operations in the economy, could distort non-participating workers' search incentives as well. Any such ALMP-induced drop in $s$ may be larger during periods of weak labour-market conditions, given that in such periods the likelihood for an individual to receive a job-offer through increased search effort is small anyway (Bloemen, 2005; Krueger \& Mueller, 2011; DeLoach \& Kurt, 2013) ${ }^{6}$. Accordingly, at the macroeconomic level, $s$ could be related to $\theta$ and $q$ like in (5):

$$
\begin{gathered}
s=s_{o}[1-\zeta(q) / \varepsilon(\theta)]>0 \\
\varepsilon_{\theta}>0, \zeta_{q} \geq 0
\end{gathered}
$$

\footnotetext{
${ }^{6}$ An alternative view is that prospect of program-participation will be seen by non-participating workers as a burden due to locking-in costs or leisure costs, inducing them to search more intensively (see e.g. Berg et.al. (2009)). In this case, the combined effect at the macroeconomic level (i.e. impact of ALMPs on average job-search effort in the economy through the response of individuals currently participating and currently not participating in programs) will be a priori unclear. However, any ALMP-induced net drop in $s$ could still be more pronounced during periods of weak labour-market conditions, given that in such periods the likelihood for an individual to receive a job-offer through more intensive search is small anyway.
} 
$\varepsilon(\theta)$ links workers' search-intensity-decision to the state of the labour market, while, for a given $\theta, \zeta_{q}>0$ allows for the possibility of an adverse effect of implementing active labour-market policies on average job-search effort in the economy. $s_{o}$ represents other (given) elements influencing the search-intensity-decision, including valuation of leisure.

Assuming further a standard (bilateral) wage-bargaining structure, where workers and firms seek to maximize their respective matching surplus, $\theta$ and the wage rate $w$ can be obtained as the outcome of a maximization problem like (6a):

$$
\left.\max _{w}\left(P_{e}-P_{u}\right)^{\beta_{1}}\left(P_{j}-P_{v}\right)^{1-\beta_{1}}, \quad \beta_{1}=\beta_{o}[1+b(q)]>0, \quad b_{q} \unlhd\right)
$$

where $\beta_{1}$ measures workers' market power, which could be affected by economy's ALMP-intensity, while $P_{u}, P_{e}$ and $P_{j}, P_{v}$ are value functions for workers and firms respectively, reflecting expected payoffs from unemployment/ employment and from filled jobs/unfilled vacancies. The $P_{i}{ }^{\prime} s$, on which ALMPs may have an impact, can be described by simplified Bellman equations ${ }^{7}$ of the form given in (6b)-(6e), where, assuming risk neutral agents, the real interest rate $r$ is used as a discount factor:

$$
\begin{gathered}
r P_{u}=\operatorname{sm}_{r}\left(P_{e}-P_{u}\right)+v(s, z)+h_{1}(q)+\dot{P}_{u} \\
r P_{e}=w-\xi\left(P_{e}-P_{u}\right)+h_{2}(q)+\dot{P}_{e} \\
r P_{j}=(\rho-w \omega)-\xi\left(P_{j}-P_{v}\right)+\dot{P}_{j} \\
r P_{v}=-\kappa+\left(m_{r} / \theta\right)\left(P_{j}-P_{v}\right)+\dot{P}_{v} \\
\text { with } \quad v_{s}<0, v_{z}>0, h_{1 q}, h_{2 q} \geq 0, \omega=\left[1-\omega_{1}(q)\right]>0, \omega_{1 q} \geq 0, \omega_{q} \leq 0 \\
r=\alpha(y / k)-\delta, \rho=\left[A_{o} E(q)(k / y)^{a}\right]^{1 /(1-a)}
\end{gathered}
$$

Starting from (6b)-(6c), a laid off individual $i$ finds a job with probability $s_{i} m_{r}$, which depends on his/her own search effort $s_{i}$ and the economy-wide job-matching rate $m_{r}$. This makes him better off by $\left(P_{e i}-P_{u i}\right)$, although greater search effort itself is associated with disutility due to reduced leisure time $\left(v_{s i}<0\right)$. A laid-off worker also enjoys utility from (exogenous) unemployment compensation $z_{i}\left(v_{z i}>0\right)$, while he/she faces the probability of program participation $h_{1 i}($.$) ,$ which, other things equal, depends positively on the economy's ALMP-intensity q. And although program-participation is associated with a leisure cost, it can be compensating ( $\left.h_{1 q i} \geq 0\right)$, both in terms of a perceived productivity gain, through additional market experience or enhanced skills and thus improved employment prospects, and in terms of improved self-assessment and better psychological health-status (Krueger \& Mueller, 2011; Cutts et.al., 2014). On the other hand, an employed individual receives the wage $w_{i}$, faces a (given) probability $\xi_{i}$ that his/her job will end, in which

\footnotetext{
${ }^{7}$ See e.g. the standard model of Pissarides (2000). See e.g. Calmfors \& Lang (1995), Filges \& Larsen (2005), Boone \&Van Ours (2009), Cahuc \& Le Barbanchon (2010), Albrecht et.al. (2009) and Gautier et.al. (2015) for more elaborated Bellman equations in the context of labour-market models that allow for skill heterogeneity or other aspects of the search \& matching decision.
} 
case welfare will drop by $\left(P_{e i}-P_{u i}\right)$, while he/she can expect, by reasoning similar to $h_{1 i}($.$) (Calmfors \& Lang, 1995),$ to obtain net utility from participating in e.g. programs involving on-the-job training, which enhance skills and reduce out-of-work risk $\left(h_{2 q i} \geq 0\right)$.Accordingly, at the aggregate level, assuming symmetry across individuals, the value functions for laid-off and employed workers will satisfy (6b)-(6c). Turning to (6d)-(6e), a destroyed job reduces a firm's profit by $\xi_{i}\left(P_{j i}-P_{v i}\right)$, while a matched vacancy raises profit by $\left(\rho_{i}-w_{i} \omega_{i}\right)$, where $\rho$ is average product of labour (defined in (6f)), and $w_{i} \omega_{i}$ is net (unit) wage cost, adjusted for the firm's perceived probability $\omega_{1 i}$ of obtaining an ALMP wage-subsidy, which, among other factors, depends on the scale of ALMP-operations in the economy $\left(\omega_{q i} \leq 0\right)$. On the other hand, posting a vacancy is costly, causing a drop in profit by $\kappa_{i}$ per-unit, while a matched vacancy increases profit by $\left(m_{r} / \theta\right)\left(P_{j i}-P_{v i}\right)$, where $\left(m_{r} / \theta\right)$ reflects the average probability that a firm's vacancy is matched with a worker. Accordingly, at the aggregate level, assuming symmetry across firms, the value functions for filled jobs and unfilled vacancies will satisfy (6d)-(6e). Moreover, workers' overall market power may fall as a result of implementing active labour-market policies to the extent that, by improving the average competencies of the workforce and causing vacancies to be filled more quickly, ALMPs will tend to intensify job competition in the economy. Thus, in (6a), $\beta_{1 q} \leq 0$, with $\beta_{o}$ representing other, non-ALMP-related, influences on workers' bargaining power. Assuming further a perfect capital market, so that the real interest rate equals the net return to capital (marginal product of capital minus the depreciation rate, $\delta$ ), leads to an expression for $r$ as in (6f).

From the solution to the maximization problem, ${ }^{8} \theta$ follows as:

$$
\begin{aligned}
& \theta=(\rho-w \omega) \frac{m_{r}}{\kappa(r+\xi)}+\dot{\theta} \frac{(1-\gamma)}{(r+\xi)} . \\
& \text { where } w=\frac{\beta}{n}(\rho+\kappa \theta s)+\frac{1}{n}[h(q)+v(s, z)] \\
& \beta=\beta_{1} /\left(1-\beta_{1}\right), n=1+\beta \omega, h(q)=h_{1}(q)-h_{2}(q) \\
& \beta_{q}, n_{q} \leq 0, h_{q}=\left(h_{1 q}-h_{2 q}\right) \geq 0
\end{aligned}
$$

Other things equal, ALMPs will tend to raise job-creation $\theta$ through wage subsidization $\left(\omega_{q}<0\right)$ and through improved matching efficiency $\left(m_{r q}>0\right)$, while a positive effect on $\theta$ may also result from the improved average competencies of the workforce $\left(\rho_{q}>0\right)$. But as the higher $\rho$ and the ALMP-wage subsidies (via $n$ ) will induce workers to revise upwards their wage demands, there will be an offsetting effect on $\theta$ through a higher $w$. A further offsetting, wageincreasing, effect will result from higher reservation wages to the extent that ALMPs will make unemployment less frightening $\left(h_{q}>0\right),{ }^{9}$ while, if laid-off workers value welfare from lower search more than the associated higher

\footnotetext{
${ }^{8}$ In deriving (6g), use has been made of the assumption of free-entry of firms, which leads to $P_{v}=\dot{P}_{v}=0$.

${ }^{9}$ Assuming that any welfare gain from e.g. training is greater for a laid-off worker than for an employed worker at risk, it follows that $h_{q}=\left(h_{1 q}-h_{2 q}\right)>0$.
} 
probability of remaining unmatched so that in $w\left(v_{s}+\kappa \beta \theta\right)<0,{ }^{10}$ an additional negative, wage-increasing, effect on $\theta$ will also arise from any ALMP-induced drop in average job-search effort in the economy. On the other hand, to the extent that ALMPs will intensify job-competition in the economy, workers' overall market power will fall, leading to a lower $w$. Substituting out $w$, and using the expression for $m_{r}$, the rate of change of job creation, $\gamma_{\theta}=\dot{\theta} / \theta$, then follows as:

$$
\gamma_{\theta}=\omega\left[\kappa \beta \theta s+h(q)+v(s, z)-\left(\frac{\rho}{\omega}\right)\right]\left(\frac{\mu(q) \theta^{-\gamma_{1}}}{\kappa n \gamma_{1}}\right)+\frac{(r+\xi)}{\gamma_{1}}
$$

Turning to the demand side of the economy, $y$ must equal the sum of consumption, $c$, total private investment, in, and government spending, $g$, all defined in per capita terms, i.e. $y=c+i n+g$.The excess of households' income over consumption, $y-c$, equals savings $s v$ plus tax payments $\tau$, while total private investment consists of replacement investment and net additions to the capital stock, i.e. $i n=\delta k+\dot{k}$ (assuming no population growth), with $\dot{k}=d k / d t$. If agents save a proportion $s v_{y}$ of their after-tax income, it then follows that

$$
\left[s v_{y}-g *+\tau *\left(1-s v_{y}\right)\right] y=\delta k+\dot{k},
$$

where $\tau^{*}=\tau / y=\tau_{y}$, with $\tau_{y}$ representing the average tax rate, while $g^{*}=g / y$ is (per-capita) government spending as percent of (per-capita) GDP. With no option for financing public spending other than taxation, ${ }^{11}$ the government must satisfy a budget constraint:

$$
\begin{aligned}
\tau^{*}=\tau_{y} & =g^{*} \\
& =g_{1}^{*}+q \ell
\end{aligned}
$$

The first term $g_{1}$ * represents (given) government spending not related to ALMPs, while, letting the economy's ALMP intensity be represented by expenditures on active labour-market policies per labour-force member as percent of percapita GDP, the second term reflects the financing requirement of ALMPs in terms of (per-capita) GDP. Using the government budget constraint and substituting for $y$ from (1), the rate of capital accumulation, $\gamma_{k}=\dot{k} / k$, then follows as:

$$
\begin{gathered}
\gamma_{k}=s v_{y}\left(1-g_{1}^{*}-q \ell\right) A_{o} E\left(q\left(\frac{\ell(1-u)}{k}\right)^{a_{1}}-\delta\right. \\
\text { where } a_{1}=(1-\partial \varnothing \varnothing),\left(1-z_{1}-\gamma_{\ell} \ell\right.
\end{gathered}
$$

Overall, the dynamics of the economy will be determined by the stock dynamics of capital accumulation and the flow dynamics of unemployment and job creation, represented, respectively, by equations (7), (4) and (6), which, can be solved for $k, u$ and $\theta$ using (1)-(3) and (5). As $\theta$ is a jump variable (through vacancies) while $k$ and $u$ are slowlyadjusting variables, the equilibrium is a saddle point. Assuming saddle-path stability, $\theta$ will respond to any changes in the

\footnotetext{
${ }^{10}$ With $\left(v_{s}+\kappa \beta \theta\right)<0$, higher search effort causes net disutility to individuals, inducing them to revise downwards their reservation wage and accept low-paid jobs.

${ }^{11} \mathrm{~A}$ balanced-budget strategy has been followed by many countries, both in the EU and elsewhere, in recent years, especially after the global economic crisis of 2008-2010.
} 
exogenous variables of the model, including the active-labour-market-policy variable $q$, so as to place the economy on the unique stable path. With $\theta$ on the saddle-path, the behaviour over time of unemployment will be determined by (4), while, given $\theta$ and $u$, capital accumulation will follow from (7).

Assuming stability (see Appendix 1), long-run equilibrium is obtained when the (per-capita) capital stock, unemployment and job creation remain constant over time. Imposing this condition $\gamma_{k}=\gamma_{u}=\gamma_{\theta}=0$, steady-state responses of $k$, $u$ and $\theta$ to a change in the economy's ALMP-intensity $q$, keeping the other exogenous variables of the model constant, can be obtained as:

$$
\begin{gathered}
\sigma_{1} \frac{d \tilde{k}}{d q}=-s v_{y}\left(\left(1+q f_{1}\right) \ell-\left(1-\tau_{y}\right)\left[a_{1} \phi_{1} \sigma_{2}\left(\frac{d \tilde{\theta}}{d q}\right)-\frac{a_{1}}{(1-u)}\left(\frac{d \tilde{u}}{d q}\right)+E_{1}+a_{1} f_{1}\right]\right) \\
\frac{1}{(1-u)} \frac{d \tilde{u}}{d q}=-\left[\left(\mu_{1}-\zeta_{1}\right)+\left(\frac{\gamma}{\theta}+\varepsilon_{1}\right) \frac{d \tilde{\theta}}{d q}\right] u \\
\sigma_{3} \frac{d \tilde{\theta}}{d q}=\left[\frac{E_{1}}{a_{1}}-\left(\frac{a}{a_{1}}\right) \frac{\left(1+q f_{1}\right) \ell}{\left(1-\tau_{y}\right)}\right] \rho+\left[\mu_{1}-\left(\frac{r+\delta}{r+\xi}\right) \frac{\left(1+q f_{1}\right) \ell}{\left(1-\tau_{y}\right)}\right] \rho_{1}-\delta_{1}-\delta_{2} \\
\text { with } \delta_{1}=\omega h_{q}+\frac{\omega b_{2}}{\beta_{1}\left(1-\beta_{1}\right)}+w \omega_{q}>0, \delta_{2}=\rho_{4} \zeta_{1}>0
\end{gathered}
$$

where

$$
\begin{gathered}
\sigma_{1}=\frac{a_{1}(a \delta)}{k(\delta+r)}>0, \sigma_{2}=1-\frac{q \ell}{a_{1}\left(1-\tau_{y}\right)}(>0), \sigma_{3}=\frac{\gamma_{1} \rho_{1}}{\theta}+\left(\kappa \omega \beta s-\varepsilon_{1} \rho_{4}\right)+a \phi_{1}\left(1-\sigma_{2}\right) \rho_{3}>0, \\
\rho_{1}=(\rho-\omega w) n>0, \rho_{2}=[w-h(q)-v(s, z)]>0, \rho_{3}=\rho+\left(\frac{a}{a_{1}}\right)\left(\frac{r+\delta}{r+\xi}\right) \rho_{1}>0, \rho_{4}=-\omega s\left(v_{s}+\kappa \beta \theta\right)>0, \\
E_{1}=\frac{E_{q}}{E(q)}, \mu_{1}=\frac{\mu_{q}}{\mu(q)}, f_{1}=\frac{f_{q} \phi(\theta)}{\ell / \ell_{o}}, \zeta_{1}=\frac{\zeta_{q} /[\varepsilon(\theta)]}{s / s_{o}}, \phi_{1}=\frac{\phi_{\theta} f(q)}{\ell / \ell_{o}}, \varepsilon_{1}=\frac{\varepsilon_{\theta}\left[f(q) /(\varepsilon(\theta))^{2}\right]}{s / s_{o}}
\end{gathered}
$$

The effect of more expansive ALMPs on the steady-state capital stock can be positive or negative. Firstly, $\frac{d \tilde{k}}{d q}$ in (8a) depends on $\frac{d \tilde{\theta}}{d q}$, and whether or not additional ALMP-spending raises job creation in the long run is a priori unclear. The first bracketed term in (8c) reflects net productivity effects on steady-state job-creation, which, besides the contribution of active labour-market policies to the economy's average skill- and efficiency level $\left(E_{1}>0\right)$, also include adverse effects arising from the tendency for $k$ to fall as the extra taxes, resulting from the need to finance the additional programs, lead to reduced savings. The second bracketed term in (8c) reflects job-creation incentives and disincentives arising, respectively, from the improved matching efficiency $\left(\mu_{1}>0\right)$ and from firms' lower payoff from posting vacancies as the drop in savings leads to a higher real interest rate. The third term $\left(\delta_{1}{ }^{>}<0\right)$ captures effects from the impact of ALMPs on wage-setting-behaviour (i.e. potentially higher reservation wages $\left(h_{q}>0\right)$ and tougher jobcompetition $\left.\left(b_{q}<0\right)\right)$, and also wage-subsidization influences $\left(\omega_{q}<0\right)$. The last term, $\delta_{2}$, reflects, possibly adverse, reservation-wage effects $\left(\rho_{4}>0\right)$, resulting from any ALMP-induced drop in average job-search effort in the economy. 
Secondly, the sign of $\frac{d \tilde{k}}{d q}$ depends on the magnitude of $\frac{d \tilde{u}}{d q}$, and, while implementing ALMPs will tend to reduce steady-state unemployment in (8b) through greater matching efficiency $\left(\mu_{1}>0\right)$, and, if $\frac{d \tilde{\theta}}{d q}>0$, through increased job creation, any ALMP-induced drop in average search effort in the economy will work in the opposite direction $\left(-\zeta_{1}<0\right)$. Thirdly, while implementing ALMPs implies that the government absorbs resources that could have been used for investment and capital accumulation, active labour-market policies improve the economy's resource-base through increased average competencies of the workforce, greater labour supply and lower equilibrium unemployment. This leads to an expansion of output, which, by raising incomes and thus savings, releases additional resources for investment. The size of $E_{1}$ and $f_{1}$ in (8a) and of $\mu_{1}$ in (8b), which corresponds to such influences, determine the magnitude of the increase in $y$ arising from the favourable resource-base effects of ALMPs, while the smaller the initial tax rate, $\tau_{y}$, the greater the resources that become available for investment as $y$ rises. Thus, if $E_{1}, f_{1}$ and $\mu_{1}$ are sufficiently large and $\tau_{y}$ is sufficiently small, the increased savings, resulting from the higher $y$, may compensate for the resource-cost of financing the extra ALMPs (i.e. $\left(1+q f_{1}\right) \ell$ in $\left.(8 \mathrm{a})\right)$, leaving on balance a larger quantity of output available for investment and capital accumulation. In such a case, even if the net effect of active labour-market policies on steady-state job-creation is non-positive, expanding the scale of ALMP operations in the economy may well lead to a higher steady-state capital stock and thus more output-growth between steady states. In the opposite case, if $E_{1}, f_{1}$ and $\mu_{1}$ are not sufficiently large and/or $\tau_{y}$ is not sufficiently small, steady-state capital in (8a) could fall and this in turn may imply lower output-growth outside steady states.

Indeed, with $\theta$ on the saddle-path and letting $\ln y_{o}$ be an initial (per-capita) steady-state output and $\psi(t)$ the rate at which the (log of) per-capita output, $\ln y(t)$, approaches (the log of) its new steady-state valueln $\tilde{y}$, one can write as an approximation for the transitional output-dynamics (Bassanini \& Scarpetta, 2001):

$$
\text { or } \quad \begin{gathered}
\ln y(t)-\ln \tilde{y}=e^{-\psi(t)}\left(\ln y_{o}-\ln \tilde{y}\right) \\
\ln y(t)-\ln y_{o}=\left(1-e^{-\psi(t)}\right)\left(\ln \tilde{y}-\ln y_{o}\right)
\end{gathered}
$$

Taking derivatives of the model around the steady-state and using (9a), an output-growth equation can then be obtained as an approximation, of the form:

$$
\begin{gathered}
d \ln y(t)=\pi(t) F\left(s v_{y}, A_{o}, \beta_{o}, z, g_{1}{ }^{*}, \ell_{o}, s_{o}, q\right)-\pi(t) \ln y \\
\text { where } \\
d \ln y(t)=\frac{\ln y(t)-\ln y_{0}}{t}, \quad \pi(t)=\frac{\left(1-e^{-\psi(t)}\right)}{t}>0 \\
F_{s v_{y}}=\frac{\lambda_{2}}{s v_{y}}, F_{A_{o}}=\frac{(1+v \rho)}{a_{1} A_{o}}, F_{\beta_{o}}=-\frac{v \rho_{2}}{\left(1-\beta_{1}\right) \beta_{o}}, F_{z}=-v \omega v_{z}, F_{g_{1} *}=-\left(\frac{\lambda_{2}}{1-\tau_{y}}\right) \\
F_{\ell_{o}}=\left[1-\lambda_{2}\left(\frac{q \ell}{1-\tau_{y}}\right)\right]\left(\frac{1}{\ell_{o}}\right), \quad F_{s_{o}}=\left(u+v \rho_{4}\right)\left(\frac{1}{s_{o}}\right)
\end{gathered}
$$




$$
\begin{gathered}
F_{q}=\left[E_{2}+f_{1}+\omega_{2}\right]+\left(\mu_{2}-\zeta_{1} u\right)-\lambda_{2}\left[\frac{\left(1+q f_{1}\right) \ell}{1-\tau_{y}}\right]-v \chi \\
\text { with } \chi=\omega h_{q}+\frac{\omega b_{q} \rho_{2}}{\beta_{1}\left(1-\beta_{1}\right)}+\rho_{4} \zeta_{1}>0
\end{gathered}
$$

and

$$
\begin{gathered}
v=\sigma / \sigma_{2}>0, \quad \sigma=\left(\frac{\gamma}{\theta}+\varepsilon_{1}\right) u+\phi_{1}\left(a_{1}+a \sigma_{3}\right)>0 \\
E_{2}=\frac{E_{1}(1+v \rho)}{a_{1}}>0, \omega_{2}=-v w \omega_{q}<0, \mu_{2}=\mu_{1}\left(u+v \rho_{1}\right)>0, \lambda_{2}=\left(1+v \rho_{3}\right)\left(\frac{a}{a_{1}}\right)>0
\end{gathered}
$$

The signs of $F_{s v_{y}}$ and $F_{A_{o}}$, which reflect the response of output-growth to an increase in the saving rate and in autonomous efficiency, are positive, while the signs of $F_{\beta o}, F_{z}$ and $F_{g_{1} *}$, which reflect output-growth responses to a rise in workers' autonomous market power, unemployment-compensation opportunities and non-ALMP-related government spending, are negative. $F_{s o}$ and $F_{\ell_{o}}$ are also most likely to be positive. On the other hand, the sign of $F_{q}$ is ambiguous. $F_{q}$ weighs the output-growth benefits from ALMPs, which are likely to result from the improved workforce-quality and overall efficiency, the higher labour-force participation, the increased job-matching rate and the enhanced job-creation incentives due to the wage subsidies, against the resource cost of implementing active labour-market policies and any ALMP-induced drop in average search effort in the economy, as well as against other, possibly adverse, side-effects of ALMPs associated with wage-setting behaviour $(\chi>0)$. The larger is the (direct and indirect) output-growth gain from the impact of ALMPs on average productivity and efficiency in the economy through improved skills and knowledge spillovers $\left(E_{2}>0\right)$, and the more positive is the impact of ALMPs on labour supply through the population's increased employment-prospects $\left(f_{1}>0\right)$ and on job-creation incentives through wage subsidization $\left(\omega_{2}>0\right)$, the greater will be the magnitude of the first (bracketed) term in $F_{q}$. Similarly, the larger is the (direct and indirect) output-growth gain from the higher job-matching efficiency $\left(\mu_{2}>0\right)$, and the less pronounced is any ALMP-induced drop in average job-search effort in the economy $\left(-\zeta_{1}<0\right)$, the more probable it is that the second term in $F_{q}$ will on balance be positive and large in size. At the same time, there is an unambiguously negative effect on output growth, the third term, as additional ALMPs require funding, which reduces the resources available for investment. This causes output-growth to fall $\left(-\lambda_{2}<0\right)$, both directly, via a lower $k$, and indirectly, via weakened job-creation incentives as the drop in labour productivity and the rise in the real interest rate associated with the falling $k$ lowers firms' payoff from posting new vacancies. This growthdecreasing effect of additional programs will tend to be more pronounced the more severe is the resource constraint in the economy, i.e. the larger is $\frac{\left(1+q f_{1}\right) \ell}{1-\tau_{y}}$ (ALMP-spending in terms of GDP relative to the resources available for other uses), and thus the more unfavourable is the overall economic context. At the same time, weak labour-market conditions, reflected in a falling $\theta$, will tend to make a large labour-supply gain less probable, reducing the magnitude of the first bracketed term in $F_{q}$ through a lower $f_{1}$. Weak labour-market conditions could also increase the magnitude of 
any ALMP-induced drop in average job-search effort in the economy, thus leading, through the size of the second term in $F_{q}$, via a larger $\zeta_{1}$, to a smaller output-growth gain. Moreover, as $\sigma$, and thus $v$, is decreasing in $\theta$ and increasing in $u$, any net adverse, wage-increasing, effect of ALMPs $(\chi>0)$ will tend to have more pronounced negative consequences for output-growth when overall economic conditions are unfavourable.

Indeed, from (9b)-(9c), it follows that the net outcome in terms of output growth from more expansive active labour-market policies is a priori unclear. At the same time, this outcome may not be independent of the state of the economy. If the existing economic environment is sufficiently satisfactory relative to trend, so as to preclude the possibility of a sizable resource-cost effect of ALMPs, of a small labour-supply gain and of a large ALMP-induced drop in average job-search effort, and thus ensure that wage-subsidization influences and the productivity- or matchingefficiency gains from implementing active labour-market policies are not fully offset, the sign of $F_{q}$ may well be positive implying a net growth-increasing effect from expanding the scale of ALMP-interventions in the economy. By contrast, if the existing economic context is not sufficiently satisfactory, so as to ensure a relatively large ALMPinduced labour-supply increase and guarantee that the resource cost of implementing active labour-market policies or any other adverse side-effects of ALMPs are small, the sign of $F_{q}$ may well be negative implying no output-growth gain from more expansive ALMPs.

\section{Empirical estimation}

To test for the existence of a causal relationship between ALMP-spending and per-capita output growth and also examine its sensitivity to cyclical influences we use a specification of the form shown in (10a)-(10c) that broadly corresponds to the structural context of Section 3:

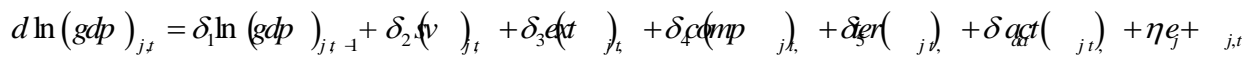

$$
\begin{aligned}
& \text { and } \\
& d \ln (g d p)_{j, t}=\delta_{1} \ln (g d p)_{j, t-1}+\delta_{2}(s v)_{j, t}+\delta_{3}(e x t)_{j, t}+\delta_{4}(\operatorname{comp})_{j, t}+\delta_{5}(\text { ter })_{j, t} \\
& +\delta_{\text {act }}(a c t)_{j, t}+\delta_{\text {act*pess }}(\text { act } * \text { pess })_{j, t}+\eta_{j}+e_{j, t} \\
& d \ln (g d p)_{j, t}=\delta_{1} \ln (g d p)_{j, t-1}+\delta_{2}(s v)_{j, t}+\delta_{3}(e x t)_{j, t}+\delta_{4}(\text { comp })_{j, t}+\delta_{5}(\text { ter })_{j, t} \\
& +\delta_{\text {act }}(a c t)_{j, t}+\delta_{\text {act*down }}(a c t * \text { down })_{j, t}+\eta_{j}+e_{j, t}
\end{aligned}
$$

The $\delta_{i}{ }^{\prime} s$ are unknown constant parameters to be estimated and $e$ is a residual term. $d \ln (g d p)_{j, t}$ is (real) percapita output growth, while $\ln (g d p)_{j, t-1}$, the lagged level of (the logarithm of) real GDP per capita, will enter the regression with a negative coefficient, $\delta_{1}$, if conditional convergence applies. $(s v)_{j, t}$ is the saving rate, proxied by the share of (gross) fixed-capital formation in GDP, with $\delta_{2}$ expected to be positive. The variables $(e x t)_{j, t}$ and $(\text { comp })_{j, t}$ are used to capture autonomous influences on per-capita output-growth arising, respectively, from workers' bargaining power and unemployment-compensation opportunities. $(\text { ext })_{j, t}$ measures the extent to which, according to national 
legislation, bargaining agreements relating to wages are extended to non-participating workers and/or firms, and it is used as a proxy for workers' bargaining power that is unrelated to the scale of ALMP operations in the economy. As a large $(e x t)_{j, t}$ may lead to excessive wage demands, we expect $\delta_{3}<0 .(\operatorname{comp})_{j, t}$ measures the duration of unemployment, which, by being inversely related to workers' perceived overall unemployment-compensation opportunities, can be expected to lead to lower reservation wages whether or not ALMPs are implemented. With reservation wages and jobcreation incentives being negatively related and with per-capita output-growth and job creation being positively related, we expect $\delta_{4}>0$. In line with much of the empirical growth literature we also include in the set of regressors human capital development associated with factors other than ALMPs, with the corresponding variable $(\text { hum })_{j, t}$ measured as the ratio of tertiary-education-enrolment to the population of the corresponding age group and $\delta_{5}$ expected to be positive. $\eta_{j}$ are fixed effects, capturing time-invariant country-characteristics, including preferences towards leisure, and thus autonomous search-intensity- or labour-supply-decisions, as well as country-differences in the preferences towards government-size that is not related to ALMPs. (act) is our proxy for ALMP-intensity and a positive and statistical significant $\delta_{a c t}$ in (10a) would suggest a net growth-enhancing effect from expanding the scale of ALMP-operations in the economy during normal times.

In (10b) and (10bc) we condition the growth-ALMP relationship on the economy's business-cycle position. $(\text { down })_{j, t}$ and $(\text { pess })_{j, t}$ are dummies that capture unfavourable economic contexts, representing, respectively, the case of a downturn of economic activity relative to trend and a switch to a more pessimistic market sentiment. Indeed, (act) is likely to enter the regressions with a significantly positive coefficient if the current economic environment is satisfactory enough relative to trend, so as to preclude the possibility of a sizable resource-cost effect of implementing ALMPs, of a small labour-supply gain and of a large ALMP-induced drop in average job-search effort in the economy, and thus ensure that the wage-subsidization influences or productivity- and matching-efficiency gains from implementing active labour-market policies are not fully offset. On the other hand, (act) may enter the regressions with a non-positive coefficient if the existing economic context is not sufficiently satisfactory, so as to guarantee a large ALMP-induced labour-supply increase and ensure that the resource-cost of financing ALMPs and any negative impact on average search effort in the economy, or other adverse, wage-increasing, influences, are small. Accordingly, statistical significance of $\delta_{a c * \text { down }}, \delta_{\text {at tpaxs }}$ in (10b)-(10c) would provide evidence of an asymmetric response of percapita output-growth to more ALMPs depending on the state of the economy. And no rejection of the hypothesis $\delta_{a c t * d o w n}, \delta_{a c t * p e s s}<0$ would indicate that the growth-ALMP elasticity is negatively related to worsening economic conditions relative to trend. To construct (down) we use the cyclical component of GDP, obtained by applying a Hodrick-Prescott filter to real GDP series, and we let this variable be equal to 1 when the cyclical GDP-component is negative. For (pess) we use the OECD's Consumer Confidence Indicator (CCI) (OECD Business Tendency \& 
Consumer Opinion Indicators Database). This indicator is a survey-based measure of market opinion and a rising (falling) value indicates that market sentiment is improving (deteriorating). Thus, we let (pess) be equal to 1 when the (annualized) change in $C C I$ is negative and equal to 0 otherwise.

In addition to this standard case, we also examine two other situations of (down) and (pess) that reflect more pronounced adverse economic conditions. In the first case we let $(\text { down })_{j, t}$ take the value of unity when the current deviation of GDP from trend is negative and the change in the cyclical component is also negative. Similarly, $(\text { pess })_{j, t}$ is set equal to 1 when the change in $C C I$ is negative both in period $t$ and in period $t-1$. In the second case $(\text { down })_{j, t}$ is set equal to 1 if the current deviation of GDP from trend is negative and also the change in the cyclical component in periods $t$ and $t-1$ is negative, while (pess) ${ }_{j, t}$ is set equal to 1 when the change in $C C I$ is negative in periods $t, t-1$ and $t-2$.

Cross-country series for the ALMP-intensity variable are constructed from OECD data (Labour Market database and Employment Outlook). This variable is measured both as expenditures on active labour-market policies per labourforce member as percent of per-capita GDP, $(a c t 1)_{j, t}$, and, as a sensitivity exercise, by program-spending to GDP, $(\text { act } 2)_{j, t}$. Per-capita GDP series are constructed from OECD data (US\$, constant prices, constant exchange rates). Data on $(s v)_{j, t}$ and $(t e r)_{j, t}$ are from the World Bank (World Development Indicators database). Data on $(\text { ext })_{j, t}$ are from the AIAS database (ICTWSS, Visser, 2013) and higher values (0 to 3) indicate higher bargaining power of workers. Series for (comp) $)_{j, t}$ are from the OECD (Incidence of Unemployment by Duration) and refer to unemployment for one or more years as percent of total unemployment. Time effects are included in all specifications to control for common developments, such as worldwide improvements in technology or monetary-policy changes, which may have taken place during the period under consideration. Descriptive statistics for the variables are shown in Appendix 2.

Estimation is carried out by applying the system-GMM technique (Arellano \& Bover, 1995; Blundell \& Bond, 1998). This technique is extensively used in panel-data growth studies to control for potential endogeneities arising from the possibility that one or more explanatory variables in growth regressions may not be strictly exogenous. Indeed, a common feature of growth models is that causation between the dependent variable and right-hand-side variables may run in both directions, leading to endogeneity bias. In system-GMM estimation, lagged levels and lagged firstdifferences of right-hand-side variables are used as instruments, ensuring that the estimates reflect causation running from right-hand-side variables to the dependent variable and not vice versa. As most of the explanatory variables in (10a)(10c), including the ALMP-intensity proxies, may not be strictly exogenous to per-capita output-growth developments, all explanatory variables have been treated as potentially endogenous and have been accordingly instrumented. The statistical adequacy of the model is established when the generated residuals do not exhibit second-order autocorrelation, a condition checked by the $m_{2}$ statistic, and when the over-identifying restrictions are not rejected, a property checked by the Sargan test. 
Estimation results are reported in Tables 1-3. In all specifications, the Sargan statistic of over-identifying restrictions confirms the joint validity of the instruments used, implying that the model is well specified. The hypothesis of no second-order serial correlation is also not rejected in almost all specifications. At the same time, the coefficients of variables representing standard, non-ALMP-related, direct and indirect, influences on output-growth rates have the expected signs. Thus, there is a positive and statistically significant effect on output growth from higher savings $(s v)_{j, t}$ and from tertiary-education human capital $(\text { hum })_{j, t}$. The coefficients on $(\text { ext })_{j, t}$ and $(\text { comp })_{j, t}$ are also always significant and with the expected negative and positive sign, respectively. Moreover, the coefficient on lagged per-capita GDP is negative and significant, indicating conditional convergence for the set of countries and time period considered.

\section{[Table 1]}

In Table 1 both proxies of ALMP intensity enter positively and are statistically significant. The coefficient on (act1) in column (1) implies that increasing, during normal times, ALMP-spending per labour-force member as percent of per-capita GDP by one standard deviation raises (per-capita) output-growth by 0.0051 percentage points. The coefficient on (act2) in column (2) implies that expanding, during normal times, the amount of ALMP spending to GDP by one standard deviation can lead to an increase in per-capita output-growth by up to 0.0041 percentage point. These results provide support for the view that, on average, there is an output-growth gain from implementing active labour-market polices, and suggest that, for the countries and time-period considered, ALMP-spending has contributed to raising per-capita incomes.

\section{[Tables 2]}

On the other hand, the results in Tables 2-3 indicate that the growth-ALMP relationship is business-cycle dependent. Starting from Table 2, in column (1a) the growth effect of ALMPs during economic upturns is reflected in the coefficient on $(a c t 1)$.This coefficient is positive, with statistical significance at $5 \%$. The corresponding effect during downturns is reflected in the coefficient $\operatorname{sum} \delta_{a c t 1}+\delta_{a c t 1^{*} d o w n}$, which, while positive, is less significant. From the magnitude of the coefficient estimates it follows that the output-growth differential due to implementing active labour market policies during upturns is about twice as large as the corresponding differential during downturns, which suggests that, as far as output-growth is concerned, 'good' times indeed provide a favourable environment for expanding the scale of ALMP-operations in the economy. Analogous results are obtained in column (1b) of Table 2. Thus, while the coefficient on $($ act 2$)$, i.e. $\delta_{\text {act } 2}$, is large in size and positive at $5 \%$, implying, during upturns, a notable output-growth gain from increasing the ratio of ALMP-spending to GDP, the coefficient sum $\delta_{\text {act } 2}+\delta_{a c t 2^{*} \text { down }}$ is quite smaller, implying during downturns a statistically insignificant output-growth effect.

\section{[Tables 3]}


Allowing for pessimistic market sentiment yields broadly similar results. Column (1a) of Table 3 indicates weak growth-enhancing effects from increasing ALMP-spending per labour-force member as percent of per-capita GDP at times of unfavourable market expectations, with the corresponding coefficient sum $\delta_{\text {act } 1}+\delta_{\text {act } 1^{*} \text { pess }}$ being positive but much smaller than the coefficient on $(a c t 1)$, i.e. $\delta_{a c t 1}$, and statistically insignificant at conventional levels. In column (1b) of the table, while the estimate for $\delta_{a c t 2}$ is positive and large in size, suggesting a significant growth-increasing effect from more ALMP-spending to GDP when market sentiment is improving., the corresponding effect when market sentiment is deteriorating, reflected in the coefficient sum $\delta_{a c t 2^{*}}+\delta_{\text {act } 2^{*} \text { pess }}$, is of smaller magnitude and marginally insignificant. Indeed, the estimates indicate that the output-growth gain from expanding ALMPs during periods of deteriorating market sentiment could be between 37 and 46 percent smaller than the corresponding gain during periods of improving market-sentiment.

Turning to the other two definitions of $(\text { down })_{j, t}$ and $(\text { pess })_{j, t}$, the results suggest larger asymmetries the more unfavourable is the current economic context relative to trend. Thus, in Table 2, both in columns (2a)-(3a) and in columns (2b)-(3b), the interaction terms are significantly negative at $1 \%$ or $5 \%$. In column (2a), this still leads, during persistent downturns, to a positive growth-ALMP relationship, but the effect is not statistically significant. In columns (3a) and (2b)-(2c), the estimates suggest the possibility of an output-growth loss from expanding ALMPs at times of pronounced adverse economic conditions relative to trend, as the coefficient sums $\delta_{a c t 1}+\delta_{a c t 1^{*} d o w n}, \delta_{a c t 2}+\delta_{a c t 2 * d o w n}$ are negative.

In columns (2a) and (2b) of Table 3, while during periods of optimistic market sentiment the results suggest a significantly positive output-growth differential of between 0.0049 and 0.0055 percentage point from increasing ALMP-spending by one standard deviation, the corresponding differential during periods of persistently pessimistic market sentiment is much smaller (0.0006 and 0.0005, respectively) and statistically insignificant at conventional levels. In columns (3a) and (3b) of the table, the estimates for $\delta_{a c t 1}, \delta_{a t+2}$ are significantly positive but the coefficient sums $\delta_{a c t 1}+\delta_{a c t 1^{*} p e s s}, \delta_{a c t 2}+\delta_{a c t}$ 2pass have a negative sign and this sign is either significant at $10 \%$ (column (3a)) or only marginally insignificant (column (3b)), indicating the possibility of a growth-decreasing effect from more expansive ALMPs during periods of persistently pessimistic market expectations.

Overall, the regression results suggest that while active labour-market policies on average contribute to raising per-capita output-growth, ALMP-spending can be less or more growth-increasing depending on the state of the economy, with our estimates indicating that ALMP-interventions can have different output-growth consequences over the cycle and during periods of changing market sentiment. This differential impact of active labour-market policies at the macroeconomic level is not difficult to explain. In 'good' times, when economic conditions are improving relative to trend, the opportunity cost of allocating additional resources to ALMPs can be small and any ALMP-induced labour-supply gain large, while the possibility of a sizable negative effect of ALMPs on average job-search effort in 
the economy, or other large adverse, side-effects, on output-growth associated with wage setting, will tend to be less likely. In 'bad' times, when economic conditions are deteriorating relative to trend, the opportunity cost of financing additional ALMPs can be sizable and any increase in labour-supply small, while the likelihood of a large ALMPinduced drop in average job-search effort in the economy cannot be ruled out. This will tend to offset any favourable effect of ALMPs on output-growth resulting, for example, from the economy's improved average skill- and/or jobmatching efficiency, leading to no net output-growth gain.

\section{Concluding comments}

Over the last decade governments in many countries have been increasingly implementing active labour-market policies in an attempt to introduce more flexibility in their respective national labour markets, which is a strategy long supported by the OECD (OECD, 1996,2006) and explicitly incorporated in the EU's employment objectives (European Commission, 2006, 2015). The role of such policies in labour-market outcomes at the microeconomic level has received a great deal of attention from empirical studies. Indeed, a rich empirical literature currently exists that focuses on the micro-level effectiveness of ALMPs, with the majority of the existing studies suggesting that programs providing training, job-search assistance and wage-subsidization pay off at the individual level as they significantly increase the unemployment-exit and employment-entry probabilities of participants. On the other hand, the evidence from the macroeconomic literature on the consequences of ALMP-spending for aggregate labour-market outcomes is inconclusive, while the explicit focus on the relationship between active labour-market policies and GDP developments is scant. In particular, as far as the association between GDP developments and ALMPs is concerned, only few studies exist, examining impulse responses of output to changes in ALMP-spending based on autoregressive models. The issue of whether or not active labour-market policies matter for output growth, based on a structural model that explicitly takes into account the causal mechanisms through which labour-market variables can have an effect on the economy at the macroeconomic level, has not been investigated in the literature. At the same time, despite much discussion in the literature on the extent to which the effects of ALMPs are influenced by the business cycle, only few studies have explicitly focused on this issue and this has been done mostly in connection with the labour-market effectiveness of particular programs at the micro-level, with the existing literature providing no conclusive evidence regarding the direction of the effect.

Based on data from OECD countries during 1991-2011, we find evidence suggesting that active labour-market policies have net growth-increasing effects during normal times and this holds after controlling for other standard, direct and indirect, influences on growth rates and after dealing with the issue of potential endogeneities. On the other hand, the growth-ALMP relationship is found to be asymmetric, with our results implying that, in terms of output growth, countries are likely to gain more from additional ALMP-spending in 'good' times than in 'bad' times. Several factors could explain this asymmetry at the macroeconomic level. First, the opportunity cost of financing active labour- 
market policies, which can be expected to be higher during downturns when the strain on public-sector resources is sizable. Second the likelihood of ALMPs having only a small favourable impact on the population's incentives for labour-force entry, which can be expected to be greater in bad times when aggregate earnings are falling. Third, potential wage-increasing effects of ALMPs, which can be expected to have a larger growth-decreasing impact through disincentives for job creation when economic conditions are unfavourable relative to trend and market sentiment is pessimistic. And fourth, the possibility of a sizable ALMP-induced drop in average job-search effort in the economy, and therefore a modest overall favourable impact of ALMPs on the job-finding rate, which is more likely to arise when the state of the economy is deteriorating relative to trend and the chances of individuals to find regular jobs through increased search effort are limited anyway. Indeed, our results imply that the output-growth gain from expanding ALMPs during downturns or periods of pessimistic market sentiment can be up to fifty percent smaller than the corresponding gain during upturns or periods of optimistic market expectations. Moreover, this asymmetry increases with the degree of persistence of 'bad times', with our results suggesting the possibility of an output-growth loss from allocating additional resources to ALMPs during periods of persistently adverse economic conditions relative to trend.

Our findings have important policy implications: Is implementing ALMPs worthwhile from an overall macroeconomic perspective? And when should additional ALMP-measures be implemented? To the extent that program-spending is found to have been on average growth-increasing, our results suggest that implementing ALMPs is worthwhile from the perspective of the whole economy even when active labour-market policies do not increase much the total number of jobs in the short run. At the same time, our results suggest that if higher output-growth is policymakers' ultimate aim, there may well be a case for implementing active labour-market policies pro-cyclically.

\section{References}

Aaronson S., Fallick B., Figura A., Pingle J.F. and Wascher W.L. (2006), "The recent decline in the labour force participation rate", Brookings Papers on Economic Activity 1, pp. 69-15.

Albrecht J., van den Berg G.J. and Vroman, S. (2009), "The aggregate labor market effects of the Swedish knowledge lift program", Review of Economic Dynamics, 12, pp.129-146.

Altavilla C. and Caroleo F. E. (2006), 'Evaluating the dynamic effects of active labour policies in Italy”, Labour, 20, pp. 349-382.

Altavilla C. and Caroleo F.E. (2013), “Asymmetric effects of national-based active labour market policies”, Regional Studies, 47, pp. $1482-1506$.

Arellano M. and Bover O. (1995), “Another look at the instrumental variable estimation of error-component models”, Journal of Econometrics, 68, pp. $29-4$.

Arranz J.M., Serranno C.G and Hernanz V. (2013), “Active labour market policies in Spain: A macroeconomic evaluation”, International Labour Review, 152, pp.324-348.

Auer P., Efendioglu U. and Leschke J. (2008), Active labour market polices around the world - coping with the consequences of globalization, International Labour Office.

Baker D., Glyn A., Howell D.R. and Schmitt J. (2005), "Labour market institutions and unemployment: a critical assessment of the cross-country evidence", in Howell D.R. (ed.) Fighting unemployment: the limits of free market orthodoxy, Oxford University Press.

Bassanini A. and Scarpetta S. (2001), "The Driving Forces of Economic Growth: Panel Data Evidence for the OECD Countries", OECD Economic Studies No. 33.

Bassanini A. and Duval R. (2006). "The determinants of unemployment across OECD countries: assessing the role of policies and institutions”, $O E C D$ Economic Studies No. 42. 
Bertola G., Blau F.D. and Kahn LM. (2001), "Comparative analysis of labor market outcomes: lessons for the US from international long-run evidence", NBER Working Paper No. 8526.

Berg G.J., Bergemann A.H. and Caliendo M. (2009), "The effect of active labor market programs on not-yet treated unemployed individuals, Journal of the European Economic Association, 7, pp. 606-616.

Betcherman G., Olivas K. and Dar A. (2004), 'Impacts of active labour market programs: new evidence from evaluations with particular attention to developing and transition countries", Social Protection Discussion Paper No. 0402, World Bank.

Blanchard O. and Wolfers J. (2000), 'The role of shocks and institutions in the rise of European unemployment: The aggregate evidence', Economic Journal, 110,pp. 1-33.

Bloemen H. (2005), “Job-search intensity and labour-market transition: an empirical analysis', Journal of Human Resources, 40, pp.231-269.

Blundell R. and Bond S. (1998), 'Initial conditions and moment restrictions in dynamic panel data models", Journal of Econometrics, 87, pp. 115-43.

Blundell R., Dias M.C., Meghir C. and Reenen J.V. (2004), "Evaluating the employment impact of a mandatory job search program”, Journal of the European Economic Association, 2, pp. 569-606

Bonoli G. (2010), "The political economy of active labour market policy”, Politics \& Society, 38, pp.435-457.

Boone J. and Van Ours J. (2009), 'Bringing unemployed back to work: effective active labour market policies”, De Economist, 157, pp. $293-313$.

Bouis R., Causa O., Demmou L., Duval R. and Zdzienicka A. (2012), "The short-term effects of structural reforms: an empirical analysis", OECD Economics Department Working Paper No 26/2012.

Brown A. and Koettl J. (2015), “Active labor market programs-employment gain or fiscal drain?”, IZA Joumal of Labor Economics, 4, pp.12-36.

Caliendo M. and Schmidl R. (2016), "Youth unemployment and active labour-market policies in Europe”, IZA Journal of Labour Policy, 5, pp.1-24.

Calmfors L.and Lang H. (1995),'Macroeconomic effects of active labour-market programs', Economic Journal, 105, pp. $601-619$.

Calmfors L., Forslund A. and Hemström M. (2002), 'Does active labour market policy work? Lessons from Swedish experiences”, Swedish Economic Policy Review, 8, pp.61-131.

Card D., Kluve J. and Weber A. (2010), “Active labour-market policies evaluations: a meta-analysis”, Economic Journal, 120, pp. $452-477$.

Card, D.,Kluve, J. and Weber, A.(2015), “What works? A meta analysis of recent active labor market program evaluations”, IZA Discussion Paper No. 9236.

Casey, B.H. (2004),'The OECD jobs strategy and the European employment strategy - Two views of the labour market and the welfare state", European Journal of Industrial Relations, 10, pp. 329-352.

Cahuc P. and Le Barbanchon T. (2010), “Labor market policy evaluation in equilibrium: Some lessons of the job search and matching model”, Labour Economics, 17, pp. 196-205.

Crépon B., Duflo E., Gurgand M., Rathelot R. and Zamora P. (2013), "Do labor market policies have displacement effects? Evidence from a clustered randomized experiment', Quarterly Journal of Economics, 128, pp. 531-580

Crépon B. and van den Berg G.J. (2016). “Active Labor Market Policies”, IZA Discussion Paper No. 10321.

Coutts A., Stuckler D. and Cann D. (2014), "The health and wellbeing effects of active labour-market policies”, in Huppert F. and Cooper C. (eds.) Interventions and policies to enhance wellbeing, Wiley.

Dahlberg M. and Forslund A. (2005), 'Direct displacement effects of labour market programs”, Scandinavian Journal of Economics, 107, pp. $475-494$.

Dauth W., Hujer, R. and WolfK. (2010), 'Macroeconomic evaluation of active labour market policies in Austria”, IZA Discussion Paper No 5217.

DeLoach S. B. and Kurt M. (2013), "Discouraged workers: estimating the impacts of macroeconomic shocks on the search intensity of the unemployed", Journal of Labour Research, 34, pp. 433-454.

De Serres A. and Murtin F. (2013), "Do policies that reduce unemployment raise its volatility? Evidence from OECD countries", OECD Economics Department Working Paper No. 1020.

De Serres A. and Murtin F. (2014), 'Unemployment at risk: the policy determinants of labour market exposure to economic shocks, Economic Policy, 29, pp. 603-637.

Duell N. and Vogler-Ludwig K. (2012), Can active labour market programmes reduce long-term unemployment? Mutual-Learning Program for Employment \& Social Solidarity, European Commission.

Elmeskov J., Martin J.P. and Scarpetta S. (1998), “Key lessons for labour market reforms: evidence from OECD countries' experience”, Swedish Economic Policy Review, 5, pp. 22-38.

Erceg C. J. and Levin A.T. (2014), "Labor force participation and monetary policy in the wake of the Great Recession", Journal of Money, Credit and Banking, 46, pp.3-49.

Escudero V. (2015), "Are active labour market policies effective in activating and integrating low-skilled individuals? An international comparison", ILO Research Department Working Paper No 3/2015.

Estevão M. (2007), “Labour policies to raise employment”, IMF Staff Papers, 54, pp. 113-138.

European Commission (2006), Employment in Europe 2006, Directorate-General for Employment, Social Affairs \& Equal Opportunities.

European Commission (2015), Guidelines for the employment policies of the member states, Council Decision (EU) 2015/1846.

Fallick B. and Fleischman C. (2004), "Employer-to-employer flows in the US labour market: The complete picture of gross worker flows”, Division of Research \& Statistics and Monetary Affairs, Federal Reserve Board.

Ferracci M, Jolivet G and van den Berg G.J. (2014), "Evidence of treatment spillovers within markets", Review of Economics \& Statistics, 96, pp. 812823.

Fertig M., Schmidt C. and Schneider H. (2006), “Active labour market policy in Germany-is there a successful strategy?”, Regional Science and Urban Economics, 36, pp. 399-430.

Filges T. and Larsen B. (2005), “Stick, Carrot and Skill Acquisition”, Scandinavian Journal of Economics, 107, pp. $495-519$. 
Forslund A., Fredriksson P.and Vikström J. (2011), 'What active labour market policy works best in a recession?', Nordic Economic Policy Review, 1, pp. 71-102.

Gautier P., Muller P., Van der Klaauw B., Roslholm M. and Svarer M. (2015), “Estimating equilibrium effects of job search assistance”, CESifo Working Paper No. 5476.

Hujer R. and Zeiss C. (2006), "Macroeconomic effects of short-term training measures on the matching process in West Germany", IZA Discussion Paper No 2489.

Hujer R., Rodrigues, P. and Wolf K. (2009), 'Estimating the macroeconomic effects of active labour market policies using spatial econometric methods", International Journal of Manpower, 30, pp. 648-671.

Johansson K. (2001), 'Do labour market programs affect labour force participation?”, Swedish Economic Policy Review, 8, pp. $215-234$.

Kluve J. (2010), "The effectiveness of European active labour market policies", Labour Economics, 17, pp. 904-918.

Krueger A. and Mueller A. (2011), "Job search, emotional well-being, and job finding in a period of mass unemployment: evidence from high frequency longitudinal data", Brookings Papers on Economic Activity 2, pp. 1-57.

Kuddo A. (2009), "Employment services and active labour market programs in Eastern \& Central Asian countries", Social Protection \& Labour Discussion Paper No. 0918, World Bank.

Lechner M. and Wunsch C. (2009), “Are training programs more effective when unemployment is high?”, Labour Economics, 27, pp.653-692.

Lise J., Shannon S. and Smith J. (2004), "Equilibrium policy experiments and the evaluation of social programs”, NBER Working Paper 10283.

Martin J.P. (2015), "Activation and active labour market policies in OECD countries: stylized facts and evidence on their effectiveness", IZA Journal of Labor Policy, 4, pp. 4-26.

McVicar D. and Podivinsky J.M. (2010), “Are active labour market programs least effective when are most needed?", Melbourne Institute Working Paper No. 16/10.

Nickell S. (1977), “Unemployment and labor market rigidities: Europe versus North America”, Journal of Economic Perspectives, 11, pp. 55-74.

OECD (1996), The OECD Job Strategy - Pushing ahead with the strategy, OECD Publishing.

OECD (2005), "Labour market programs and activation strategies - evaluating the impacts", in OECD Employment Outlook 2005, OECD Publishing.

OECD (2006), "Boosting Jobs and Incomes - The reassessed job strategy”, in OECD Employment Outlook 2006, OECD Publishing.

OECD (2015), “Activation policies for more inclusive labour markets", in OECD Employment Outlook 2015, OECD Publishing

Petrongolo B. and Pissarides C. (2001), 'Looking into the black box: a survey of the matching function”, Joumal of Economic Literature, 39 , pp. $390-431$.

Pissarides C. (2000), Equilibrium Unemployment Theory, MIT Press.

Røed K. and Raaum O. (2006), “Do labour market programmes speed up the return to work?”, Oxford Bulletin of Economics and Statistics, 68, pp. 541-568.

Rosholm M. and Skipper L. (2009), 'Is labour market training a curse for the unemployed? Evidence from a social experiment", Journal of Applied Econometrics, 24, pp. 338-365.

Scarpetta S. (1996), "Assessing the role of labour market policies and institutional settings on unemployment: a cross-country study", OECD Economic Studies No 26.

Staghøj, J., Svarer, M. and Rosholm, M. (2007), “A statistical programme assignment”, IZA Discussion Paper 3165.

Van Ours J.C. (2004), “The locking-in effect of subsidized jobs”, Journal of Comparative Economics, 32, pp. 37-52.

Van Zandweghe W.(2012), “Interpreting the recent decline in labor force participation”, Economic Review-Federal Reserve Bank of Kansas City, pp. 5-30.

Visser, J. (2013), ICTWSS: Database on institutional characteristics of trade unions, wage setting, state intervention and social pacts (Version 4), Amsterdam Institute for Advanced Labour Studies (AIAS), University of Amsterdam.

Zervoyianni A., Anastasiou A.T. and Anastasiou A. (2014), 'Does central bank independence really matter? Re-assessing the role of the independence of monetary policymakers in macroeconomic outcomes", International Journal of Economics \& Business Research, 8, pp. $427-473$. 


\section{Appendix 1}

Taking time derivatives in (7), (4) and (6) and using (1)-(3) and (5), the linearized dynamics of the system can be represented by:

$$
\left[\begin{array}{l}
\hat{\gamma}_{k}(t) \\
\hat{\gamma}_{u}(t) \\
\hat{\gamma}_{\theta}(t)
\end{array}\right]=C\left[\begin{array}{l}
\hat{k}(t) \\
\hat{u}(t) \\
\hat{\theta}(t)
\end{array}\right]+H_{1} \hat{q}+H_{2} \hat{x} \text {, with } C=\left[\begin{array}{ccc}
c_{11} & c_{12} & c_{13} \\
c_{21} & c_{22} & c_{23} \\
c_{31} & c_{32} & c_{33}
\end{array}\right]
$$

where

$$
\begin{gathered}
c_{11}=-\frac{a_{1} \delta}{k\left(1-\tau_{y}\right)^{2}}<0, c_{12}=-\frac{a_{1} \delta}{\left(1-\tau_{y}\right)(1-u)}<0, c_{13}=\frac{a_{1} \delta}{\left(1-\tau_{y}\right)}\left[1-\frac{q \ell}{a_{1}\left(1-\tau_{y}\right)}\right] \phi_{1}(>0), \\
c_{21}=0, c_{22}=-\frac{\xi}{u^{2}}<0, c_{23}=-\left(\frac{\gamma}{\theta}+\varepsilon_{1}\right) \frac{\xi(1-u)}{u}<0, c_{31}=\frac{(r+\xi) \rho_{4}}{\delta \gamma_{1} \rho_{1}}\left(\frac{a}{a_{1}}\right) c_{11}<0, \\
c_{32}=\frac{(r+\xi) \rho_{4}}{\delta \gamma_{1} \rho_{1}}\left(\frac{a}{a_{1}}\right) c_{12}<0, c_{33}=\frac{(r+\xi) \sigma_{2}}{\gamma_{1} \rho_{1}}+\frac{(r+\xi) \rho_{4}}{\delta \gamma_{1} \rho_{1}}\left(\frac{a}{a_{1}}\right) c_{13}>0
\end{gathered}
$$

The circumflex over the variables denotes deviations from an initial steady state. $C$ is the state matrix and $H_{1}\left(H_{2}\right)$ is a vector (matrix) reflecting effects from a change in the ALMP-variable $q$ (a change in the other exogenous variables of the model, $x$ ). The determinant of the state matrix, which equals the product of the three roots of the system, i.e. $\varphi_{1} \varphi_{2} \varphi_{3}$, is positive, implying either one or three positive roots. The coefficient sum $-c_{11}\left(c_{33}+c_{22}\right)-c_{22} c_{33}+c_{32} c_{23}+c_{13} c_{31}$, which, from the characteristic equation of the system, equals $-\left(\varphi_{1} \varphi_{2}+\varphi_{2} \varphi_{3}+\varphi_{1} \varphi_{3}\right)$, is also almost certainly positive, implying that some roots must be negative. This suggests that the system has two negative roots and one positive root and thus is saddle-path stable.

\section{Appendix 2}

\section{Descriptive statistics}

\begin{tabular}{cccccc}
\hline \hline Variable & Obs. & Mean & Std. Dev. & Min & Max \\
\hline $\ln (g d p)_{j, t}$ & 482 & 0.0175 & 0.0246 & -0.0940 & 0.0973 \\
$\ln (g d p)_{j, t}$ & 482 & 10.1743 & 0.5503 & 8.4469 & 11.1251 \\
$(s v)_{j, t}$ & 482 & 0.2148 & 0.0342 & 0.1194 & 0.3203 \\
$(\text { ext })_{j, t}$ & 482 & 1.4917 & 1.2441 & 0 & 3 \\
$(\text { comp })_{j, t}$ & 482 & 0.3144 & 0.1638 & 0.0033 & 0.7544 \\
$(\text { ter })_{j, t}$ & 482 & 0.5567 & 0.1870 & 0.1471 & 1.0387 \\
$(\text { act } 1)_{j, t}$ & 457 & 0.0109 & 0.0086 & 0.0002 & 0.0530 \\
$(\text { act } 2)_{j, t}$ & 482 & 0.0054 & 0.0043 & 0.0001 & 0.0266 \\
\hline \hline
\end{tabular}

Country-sample: Australia, Austria, Belgium, Canada, Czech Republic, Denmark, Finland, France, Germany, Greece, Hungary, Ireland, Israel, Italy, Japan, Korea, Mexico, Netherlands, New Zealand, Norway, Poland, Portugal, Spain, Sweden, Switzerland, United Kingdom, United States. The country sample follows from data availability for all the variables. Time-period: 1991-2011. 
Table 1 Per-capita output-growth and active labour-market policies

\begin{tabular}{|c|c|c|}
\hline Regressor & (1) & (2) \\
\hline $\ln (g d p)_{j, t-1}$ & $\begin{array}{c}-0.014^{* *} \\
(-230)\end{array}$ & $\begin{array}{c}-0.014^{* * *} \\
(-239)\end{array}$ \\
\hline$(s v)_{j, t}$ & $\begin{array}{c}(-2.50) \\
0.241^{* * *} \\
(3.76)\end{array}$ & $\begin{array}{c}(-2.39) \\
0.247^{* * *} \\
(3.39)\end{array}$ \\
\hline$(e x t)_{j, t}$ & $\begin{array}{c}-0.010^{* * * *} \\
(-4.19)\end{array}$ & $\begin{array}{c}-0.009^{* * *} \\
(-3.10)\end{array}$ \\
\hline$(\text { comp })_{j, t}$ & $\begin{array}{c}0.096^{* * * *} \\
(6.17)\end{array}$ & $\begin{array}{c}0.097^{* * * *} \\
(5.59)\end{array}$ \\
\hline$(t e r)_{j, t}$ & $\begin{array}{l}0.046^{\text {*** }} \\
(2.43)\end{array}$ & $\begin{array}{c}0.043^{* *} \\
(2.33)\end{array}$ \\
\hline$(a c t 1)_{j, t}$ & $\begin{array}{l}0.595^{*} \\
(1.94)\end{array}$ & \\
\hline$(a c t 2)_{j, t}$ & - & $\begin{array}{l}0.956^{*} \\
(1.71)\end{array}$ \\
\hline Observations & 457 & 482 \\
\hline$m_{l}(p$-value $)$ & 0.01 & 0.01 \\
\hline$m_{2}(p$-value $)$ & 0.31 & 0.10 \\
\hline Sargan (p-value) & 0.97 & 0.73 \\
\hline
\end{tabular}

Notes: Numbers in parentheses denote z-scores, $m_{1}$ and $m_{2}$ are residual first and second order serial correlation tests, while Sargan stands for the over-identifying restrictions test. Single, double, and triple asterisks denote statistical significance at the ten percent, five percent, and one percent level respectively. The model allows for robust standard errors. The instruments used in each model correspond to the t-2 to t-3 lags of the explanatory variables. Time dummies are included in all specifications. 
Table 2 Per-capita output growth and ALMP-spending: allowing for asymmetries across states of business cycle

\begin{tabular}{|c|c|c|c|c|c|c|}
\hline Regressor $^{1}$ & $(1 a)^{a}$ & $(2 a)^{b}$ & $(3 a)^{c}$ & $(1 b)^{a}$ & $(2 b)^{b}$ & $(3 b)^{c}$ \\
\hline $\ln (g d p)_{j, t-1}$ & $\begin{array}{l}-0.015^{* * * *} \\
(-2.73)\end{array}$ & $\begin{array}{l}-0.013^{* * *} \\
(-2.28)\end{array}$ & $\begin{array}{l}-0.014^{* *} \\
(-2.47)\end{array}$ & $\begin{array}{l}-0.016 \\
(-2.98)\end{array}$ & $\begin{array}{l}-0.013^{* *} \\
(-2.28)\end{array}$ & $\begin{array}{l}-0.015^{\text {****** }} \\
(-2.68)\end{array}$ \\
\hline$(s v)_{j, t}$ & $\begin{array}{l}0.190^{* * * *} \\
(3.03)\end{array}$ & $\begin{array}{l}0.202^{* * * *} \\
(3.23)\end{array}$ & $\begin{array}{l}0.196^{* * *} \\
(3.51)\end{array}$ & $\begin{array}{l}0.190^{* * *} \\
(2.87)\end{array}$ & $\begin{array}{l}0.204^{* * * *} \\
(2.99)\end{array}$ & $\begin{array}{c}0.207^{* * * *} \\
(3.23)\end{array}$ \\
\hline$(e x t)_{j, t}$ & $\begin{array}{l}-0.009^{* * *} \\
(-4.28)\end{array}$ & $\begin{array}{l}-0.010^{* * *} \\
(-4.46)\end{array}$ & $\begin{array}{l}-0.010^{* * * * *} \\
(-4.21)\end{array}$ & $\begin{array}{l}-0.008^{* * * *} \\
(-3.36)\end{array}$ & $\begin{array}{c}-0.010^{* * * *} \\
(-3.66)\end{array}$ & $\begin{array}{c}-0.010^{\text {**** }} \\
(-3.65)\end{array}$ \\
\hline$(\text { comp })_{j, t}$ & $\begin{array}{l}0.089^{* * * *} \\
(6.61)\end{array}$ & $\begin{array}{l}0.091^{* * * *} \\
(6.29)\end{array}$ & $\begin{array}{l}0.083^{* * * *} \\
(5.64)\end{array}$ & $\begin{array}{l}0.087^{* * * *} \\
(5.62)\end{array}$ & $\begin{array}{l}0.093^{* * * *} \\
(5.86)\end{array}$ & $\begin{array}{l}0.086^{\text {***** }} \\
(5.78)\end{array}$ \\
\hline$(\text { ter })_{j, t}$ & $\begin{array}{l}0.040^{* *} \\
(2.26)\end{array}$ & $\begin{array}{l}0.042^{* *} \\
(2.34)\end{array}$ & $\begin{array}{l}0.035^{* *} \\
(1.95)\end{array}$ & $\begin{array}{l}0.039^{* *} \\
(2.31)\end{array}$ & $\begin{array}{l}0.040^{* *} \\
(2.26)\end{array}$ & $\begin{array}{l}0.035^{* *} \\
(2.02)\end{array}$ \\
\hline$(a c t 1)_{j, t}$ & $\begin{array}{l}0.623^{* *} \\
(2.11)\end{array}$ & $\begin{array}{l}0.675^{\text {** }} \\
(2.52)\end{array}$ & $\begin{array}{l}0.561^{* *} \\
(2.47)\end{array}$ & & & \\
\hline$(a c t 1 * d o w n)_{j, t}$ & $\begin{array}{l}-0.295^{*} \\
(-1.71)\end{array}$ & $\begin{array}{c}-0.579^{* * *} \\
(-2.56)\end{array}$ & $\begin{array}{c}-0.843^{\text {**** }} \\
(-3.17)\end{array}$ & & & \\
\hline$(\operatorname{act} 2)_{j, t}$ & & & & $\begin{array}{l}1.189^{* *} \\
(2.07)\end{array}$ & $\begin{array}{l}1.251^{* *} \\
(2.48)\end{array}$ & $\begin{array}{l}1.127^{* *} \\
(2.41)\end{array}$ \\
\hline$(\operatorname{act} 2 * \text { down })_{j, t}$ & & & & $\begin{array}{l}-0.654^{*} \\
(-1.71)\end{array}$ & $\begin{array}{c}-1.373^{\text {**** }} \\
(-2.99)\end{array}$ & $\begin{array}{c}-1.782^{\text {**** }} \\
(-3.25)\end{array}$ \\
\hline Observations & 457 & 457 & 445 & 482 & 482 & 466 \\
\hline$m_{l}$ (p-value $)$ & 0.01 & 0.01 & 0.00 & 0.01 & 0.00 & 0.00 \\
\hline$m_{2}(p$-value $)$ & 0.34 & 0.54 & 0.89 & 0.13 & 0.22 & 0.42 \\
\hline Sargan (p-value) & 0.95 & 0.96 & 0.97 & 0.81 & 0.81 & 0.95 \\
\hline $\begin{array}{c}\text { Hypothesis 1: } \\
\delta_{\text {act }}+\delta_{\text {act*down }}=0 \\
(p \text {-value })\end{array}$ & 0.08 & 0.74 & 0.22 & 0.11 & 0.79 & 0.10 \\
\hline
\end{tabular}

Notes: ${ }^{1}$ see Table 1; ${ }^{a}($ down $)$ is set equal to 1 if the current cyclical GDP-component is negative; ${ }^{b}($ down $)$ is set equal to 1 if the current deviation of GDP from trend is negative and the change in the cyclical component is also negative; ${ }^{c}$ (down) is set equal to 1 if the current deviation of GDP from trend is negative and the change in the cyclical components in periods $t$ and $t-1$ are also negative. 
Table 3 Per-capita output-growth and ALMP-spending: allowing for asymmetries across states of expectations

\begin{tabular}{|c|c|c|c|c|c|c|}
\hline Regressor $^{1}$ & $(1 \mathrm{a})^{\mathrm{a}}$ & $(2 a)^{b}$ & $(3 a)^{c}$ & $(1 \mathrm{~b})^{\mathrm{a}}$ & $(2 b)^{b}$ & $(3 b)^{c}$ \\
\hline $\ln (g d p)_{j, t-1}$ & $\begin{array}{l}-0.012^{* *} \\
(-2.26)\end{array}$ & $\begin{array}{l}-0.013^{* * *} \\
(-2.15)\end{array}$ & $\begin{array}{l}-0.014^{* * *} \\
(-2.30)\end{array}$ & $\begin{array}{l}-0.012^{* *} \\
(-2.22)\end{array}$ & $\begin{array}{l}-0.012^{* *} \\
(-2.22)\end{array}$ & $\begin{array}{l}-0.013^{* *} \\
(-2.15)\end{array}$ \\
\hline$(s v)_{j, t}$ & $\begin{array}{l}0.232^{* * * *} \\
(3.67)\end{array}$ & $0.228^{* * * *}$ & $\begin{array}{l}0.200^{* * * *} \\
(3.09)\end{array}$ & $\begin{array}{l}0.248^{* * * *} \\
(3.84)\end{array}$ & $\begin{array}{l}0.250^{* * * *} \\
(3.86)\end{array}$ & $\begin{array}{c}0.239^{* * * *} \\
(4.01)\end{array}$ \\
\hline$(e x t)_{j, t}$ & $\begin{array}{l}-0.006^{* * * *} \\
(-2.64)\end{array}$ & $\begin{array}{c}-0.006^{* * * *} \\
(-2.95)\end{array}$ & $\begin{array}{l}-0.006^{* * * *} \\
(-3.34)\end{array}$ & $\begin{array}{l}-0.006^{* * *} \\
(-2.66)\end{array}$ & $\begin{array}{c}-0.006^{* * * *} \\
(-2.97)\end{array}$ & $\begin{array}{l}-0.007^{* * * *} \\
(-3.53)\end{array}$ \\
\hline$(\text { comp })_{j, t}$ & $\begin{array}{l}0.076^{* * * * *} \\
(3.97)\end{array}$ & $\begin{array}{c}0.079^{* * * *} \\
(3.57)\end{array}$ & $\begin{array}{c}0.077^{* * * *} \\
(4.05)\end{array}$ & $\begin{array}{l}0.081^{* * * * *} \\
(3.99)\end{array}$ & $\begin{array}{c}0.081^{* * * *} \\
(3.78)\end{array}$ & $\begin{array}{c}0.080^{* * * * * *} \\
(4.14)\end{array}$ \\
\hline$(t e r)_{j, t}$ & $\begin{array}{l}0.069^{* * *} \\
(4.48)\end{array}$ & $\begin{array}{l}0.066^{* * *} \\
(3.84)\end{array}$ & $\begin{array}{l}0.054^{* * * *} \\
(3.50)\end{array}$ & $\begin{array}{l}0.069^{* * *} \\
(4.94)\end{array}$ & $\begin{array}{l}0.065^{* * *} \\
(4.28)\end{array}$ & $\begin{array}{l}0.058^{\text {***** }} \\
(4.14)\end{array}$ \\
\hline$(a c t 1)_{j, t}$ & $\begin{array}{l}0.692^{* * *} \\
(2.37)\end{array}$ & $\begin{array}{l}0.569^{* *} \\
(2.04)\end{array}$ & $\begin{array}{l}0.580^{* *} \\
(2.01)\end{array}$ & & & \\
\hline$\left(a c t 1^{*} \text { pess }\right)_{j, t}$ & $\begin{array}{c}-0.437^{* * * *} \\
(-3.30)\end{array}$ & $\begin{array}{l}-0.504^{* * *} \\
(-3.73)\end{array}$ & $\begin{array}{l}-1.035^{\text {**** }} \\
(-4.47)\end{array}$ & & & \\
\hline$(\operatorname{act} 2)_{j, t}$ & & & & $\begin{array}{l}1.422^{* *} \\
(2.52)\end{array}$ & $\begin{array}{l}1.289^{* *} \\
(2.52)\end{array}$ & $\begin{array}{l}1.313^{* *} \\
(2.55)\end{array}$ \\
\hline$(\operatorname{act} 2 * \text { pess })_{j, t}$ & & & & $\begin{array}{c}-0.769^{* * * *} \\
(-2.73)\end{array}$ & $\begin{array}{c}-1.166^{* * *} \\
(-3.84)\end{array}$ & $\begin{array}{c}-2.174^{* * * *} \\
(-4.19)\end{array}$ \\
\hline Observations & 376 & 364 & 349 & 398 & 383 & 365 \\
\hline$m_{l}$ (p-value $)$ & 0.00 & 0.00 & 0.00 & 0.00 & 0.00 & 0.00 \\
\hline$m_{2}(p$-value $)$ & 0.20 & 0.80 & 0.33 & 0.04 & 0.33 & 0.08 \\
\hline Sargan (p-value) & 0.93 & 0.95 & 0.97 & 0.83 & 0.88 & 0.96 \\
\hline $\begin{array}{c}\text { Hypothesis 2: } \\
\delta_{\text {act }}+\delta_{\text {act } t^{*} \text { pess }} \\
(p \text {-value })\end{array}$ & 0.27 & 0.77 & 0.09 & 0.11 & 0.76 & 0.10 \\
\hline
\end{tabular}

Notes: ${ }^{1}$ see Table $1 ;{ }^{\mathrm{a}}($ pess $)$ is set equal to 1 if the (annualized) change in $C C I$ in period $t$ is negative; ${ }^{\mathrm{b}}($ pess $)$ is set equal to 1 if the change in $C C I$ is negative both in period $t$ and in period $t-1 ;{ }^{\mathrm{c}}$ ( pess $)$ is set equal to 1 if the change in $C C I$ is negative in periods $t, t-1$ and $t-2$. Due to unavailability of data on the $C C I$ variable for Canada, Israel, New Zealand and Norway, the sample size is restricted to 23 countries. For Switzerland, we resort to the Business Confidence Indicator for manufacturing obtained from the Business Tendency \& Consumer Opinion Indicators Database, OECD. 